\title{
Analysis on the Reasons of Delta Bankruptcy
}

\author{
Panyue Chen ${ }^{1, *}$
}

\author{
${ }^{1}$ Wilmington Christian School, Hockessin, United States, 19707 \\ *Corresponding author. Email: danchen.daily@gmail.com
}

\begin{abstract}
Any field could be severely impacted by occasional stern crises. Therefore, having appropriate strategies to not only survive from the predicaments but also achieve subsequent long-term prosperity will be crucial. In this paper, Delta will be exemplified to show its successful tactics for disentangling its bankruptcy crisis that happened in 2005. The author will primarily illustrate and evaluate in two parts - the reasons that triggered its bankruptcy and the stratagems they used to exit-basically from the start of it filed bankruptcy in 2005 to the exit in 2007. In addition, through data analysis to show the importance of cost structure for a company, this paper is also meant to provide references for those companies which are on the edge of bankrupt after the coronavirus period.
\end{abstract}

Keywords: bankruptcy, Delta, post-covid period, recovery

\section{INTRODUCTION}

In the past two years, the whole world was afflicted with the effect brought by the coronavirus, which has been diffusively affecting every aspect of our daily life. The world was stagnant, and every country was searching for ways to grapple with the consequences from coronavirus. Almost all of the fields could not be free from the effects of coronavirus; the economy was greatly battered. Aviation industry as one of the most vulnerable fields was considerably impacted due to the tremendous decrease of the passengers since people barely went out [1]. In the past 5 years, the aviation industry has been losing revenue at a rate of $12.0 \%$ to $\$ 71.0$ billion per year. Only in 2020, the revenue performance declined roughly $53.8 \%$. The total loss in revenue was up to 370 billion U.S. dollars in the same period. Airline operators were searching to save as much cost as possible, like cutting capacity and discretionary spending, hiring freezes. However, the fixed high cost was not able to be eliminated such as aircraft maintenance [2]. In addition, airports were also suffering the loss of 124.8 billion U.S. dollars in 2020 and estimated further 94 billion U.S. dollars losses for 2021. Therefore, the subsequent recovery cannot wait for too long, and the way they are going to choose to recuperate will be critical. However, fortunately it is not the first huge crisis that the aviation industry ever faced, but during these past crises, some airlines took appropriate strategies to survive the crisis and recover quickly. These airlines are some good examples and deserve other companies to learn from and refer to. Delta airline company is one of them. The strategies and measures that Delta took helped itself survive from bankruptcy.

This paper evaluates the crisis that Delta have faced from the start when the airline filed commonly went bankrupt in 2005 to the exit in 2007, demonstrates the reasons for bankruptcy and proposes some suggestions to face such crisis, and provides references for those companies which are on the edge of being bankrupt after the coronavirus period.

\section{ANALYSIS OF DELTA AIRLINE}

Delta airline as one of the most prominent airlines in the world was founded in 1925, and it was named Huff Daland Duster for aerial crop service at start, which was the first aerial crop dusting operation in the world. The company set up passenger service in June 1929. After a series of affairs in the airmail contract, the company officially operated as Delta Air Lines in 1945. From 1946 to 1991, Delta Air Line experienced rapid progress and expansion, which made them in 1997 become the first airline boarding more than 110 million passengers in a year, representing a milestone in the history. Nowadays, Delta Air Lines is the second largest airline among the world, leading in the areas in fleet size, number of scheduled passengers carried, revenue passengerkilometers flown, etc. Delta Air Lines also worked as a founding member of The SkyTeam Alliance airline alliances, one of the major three airline alliances in the world. 
Since 2003, oil prices have reached record highs. Fuel cost is a huge part of the cost structure of any airline. It usually can compose $20 \%-30 \%$ of the operation expense of the airline company as the second largest cost. In fact, the price of fuel could be influenced by tremendous factors. Usually the long-term explanatory reason could be explained by the world reserve base, which can be measured by the production ability in the present year. Nevertheless, the price level of oil is normally driven by a mass of short-term factors in increasing the demand of oil: geopolitical events, natural disasters, interest rate impact, war and terrorism, etc.

According to the data from West Texas Intermediate (WTI), in Figure1, the price of oil was moderating from $\$ 22$ to $\$ 28$ per barrel. Yet, due to the Iraq War, the price has fluctuated and tended to increase for a period of time since march 2003, since Iraq is one of the countries that have the richest oil reserves, approximately $10 \%$ of world oil remaining. However, the oil price has drastically increased since september 2003 to the vertex at $\$ 53$ per barrel in October 2004, which has almost doubled in a year. Although it has decreased by almost $10 \%$, it bounced back to the top again in 2005 .

One of the major reasons behind was mainly caused by the imbalance between demand and supply that the future demand growth of crude oil was optimal, whereas the supplies in those continuing unstable countries such as Iraq, Nigeria was uncertain and limited increase production from non-Organization of Petroleum Exporting Countries (OPEC) [3].

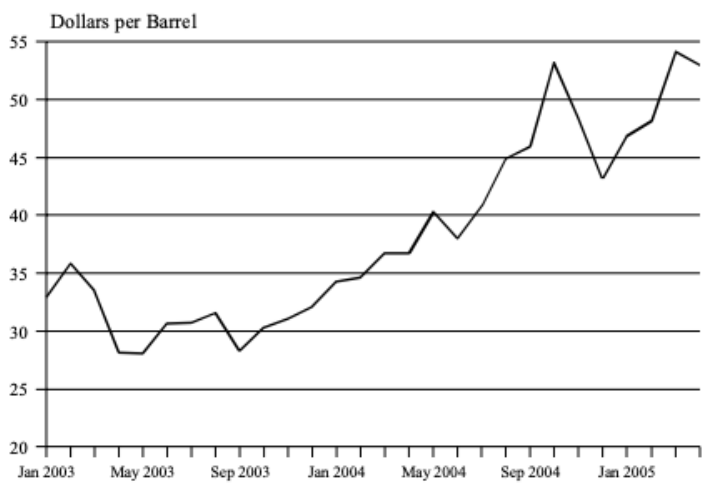

Figure 1 U.S Spot Price of oil, 2003-2005 [4]
In the meanwhile, other factors could also play a part in effecting the surge of fuel cost. For instance, Hurricane Katrina, which happened on August 23, 2005, re-boosted the prices of oil to increase again. It devastated the Gulf of Mexico, a major supplier through pipeline, and severely damaged The U.S refineries by decreasing $10 \%$ refinery capacity, causing stagnation in the production and distribution system, since the majority of oil refiners are based in the Middle East, Midwest, or the East coast. Nonetheless, it is impossible for the airlines to handle these unpredictable factors.

Massive companies had different degrees of influence from the change in oil prices like Delta Air Lines. However, filed bankruptcy is not only caused by the upgrade fuel cost but also heavy debt and pension obligations. Since 2001, Delta has lost more than $\$ 10$ billion and its total debt crudely was $\$ 28.3$ billion, the ninth-largest in U.S. history.

The pension obligation was an intractable problem. During 2004, the negotiation between Delta and the Labor Union about the retirement pension was at an impasse. Labor Union is a group by representing a group of unrepresented classes or craft of employees to seek the optimal benefits when their demands are not satisfied. The relationship between Airlines and Labor Union would be like a rat race: one always dedicates to achieving the uttermost cut in costs, whereas another strives to obtain higher wages and better welfare. Referring to the table below, the cost of labor was the dominant part in the structure of expenses in each year from 2002-2004, which approximately stands for $40 \%$, $42 \%$, and $35 \%$, respectively. 
Table 1. Delta operating expenses, 2002-2004

\begin{tabular}{|l|r|r|r|}
\hline $\begin{array}{l}\text { Operating Expenses: } \\
\text { (in millions) }\end{array}$ & \multicolumn{2}{|c|}{2004} & 2003 \\
\hline Salaries and related costs & 6338 & 6342 & 6165 \\
\hline Aircraft fuel & 2924 & 1938 & 1683 \\
\hline Contracted services & 999 & 886 & 1003 \\
\hline Aircraft rent & 716 & 727 & 709 \\
\hline Impairment of intangible assets & 1875 & -- & -- \\
\hline Passenger service & 204 & 211 & 322 \\
\hline Contract carrier arrangements & 932 & 784 & 561 \\
\hline Aircraft maintenance materials and outside repairs & 681 & 630 & 711 \\
\hline I & & & 15715 \\
\hline Total operating expenses & 18310 & 14872 & \\
\hline
\end{tabular}

To a great extent, labor expenses can determine the amount of annual cost of a carrier, which sometimes even can make a company on the verge of bankruptcy. Two examples can be seen below.

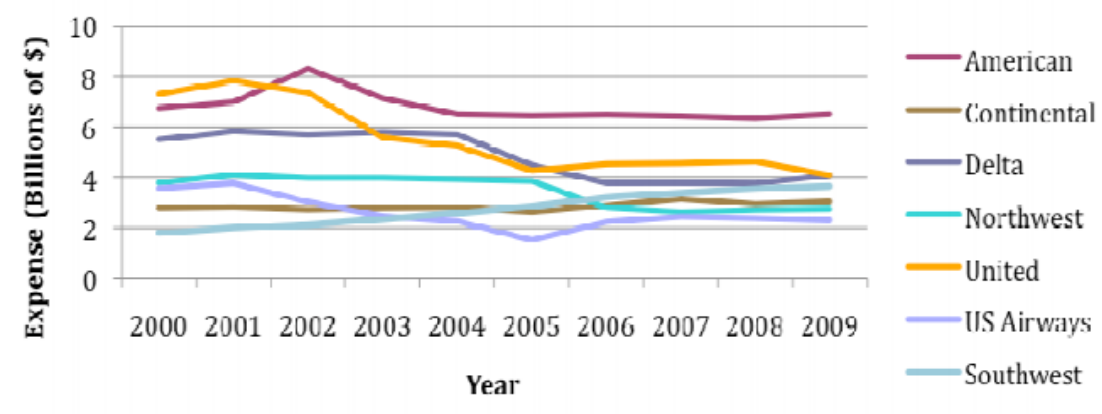

Figure 2 Total Labor Expense-Wages, Salaries \& Benefits [5]

Figure 2 shows multiple carriers' labor expenses, and American Airlines and US Airways had the top two highest labor expenses before 2003. In 2001-2002, American Airlines had the highest labor cost and suddenly dropped due to triumphant employee concessions, which made them successfully avoid bankruptcy. In addition to the case of AA, US Airways entered into bankruptcy in 2003. However, the subsequent negotiation allowed them to cut $\$ 1$ billion in the cost, avoiding liquidation. Moreover, Delta had the third-highest labor expense before they started considering reconstructing plan bankruptcy in the end of 2004. Delta's pension plans were set decades ago, and most of the plans depended on the situation of the stock market. However, in the past few years, the interest rate plummeted, which forced the company to remedy the defect to satiate the minimum requirement of pension each year. "It's like you took out a 30-year mortgage on your house, and then the stock markets fall and interest rates change and the lender comes back and says you have to pay it all back like a five-year car loan", said John Mazur, a spokesman for ALPA in Washington, D.C. [6]. At the end of year of 2002 and 2003, accumulated other comprehensive loss had a non-cash charge which was recorded to recognize a portion of our additional minimum pension liability that was equal to the excess from the accumulated benefit obligation (ABO) to fair value of the defined benefit pension plan assets, aggregating \$227 million and \$333 million at December 31, 2003 and 2002, respectively. In addition, the additional minimum pension liability adjustment, which was in accumulated other comprehensive loss on our Consolidated Balance Sheets at December 31, 2003 and 2002 (Figure3), was recorded having $\$ 776$ million and $\$ 1.6$ billion, net of tax, respectively, which portioned almost $1 / 2$ in the total comprehensive loss. 
(in millions)

Net loss
Other comprehensive loss

Comprehensive loss

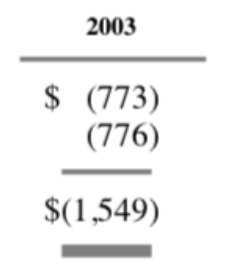

2001

$\$(1,216)$

(335)

$\$(1,551)$

Figure 3 Comprehensive loss for the years ended December 31, 2005, 2004 and 2003[7]

\section{DELTA'S SOLUTIONS IN FACING CRISES}

"If Delta is to survive, we must develop a fundamentally different way of doing business, which is what we're doing", chief executive Gerald Grinstein said during a Web-based conference with investors [8]. September. 14, 2005, the day delta officially handed in the petitionary file for reorganization under Chapter 11 .

Due to the excessive amount of debt, the primary goal for Delta was to obtain exit financing facility, which was later co-led by six financial institutions, JPMorgan, Goldman Sachs \& Co., Merrill Lynch, Lehman Brothers, UBS, and Barclays Capital, and the amount accumulated was approximately $\$ 2.5$ billion [9]. It was a remarkable step at the start of reorganization, helping them distribute a portion of the proceeds to repay a couple of Petition Facilities operated by GE Capital and Amex, and the remains would be used in the initial operation process for restructure. Moreover, selling ASA (Atlantic Southeast Airlines) to SkyWest Airlines also relieved Delta's pressure by having a receipt of $\$ 350$ millions.

Though, one of the most prominent changes that Delta made in this reorganization was to reform its network by minimizing the sizes and the types of its fleets, which took a great portion in lowering costs, and by restructuring its domestic and international routes for retrenching the cost and obtaining the financial benefits. In 2006, Delta initially retired three types of its fleets, Boeing 737-200, Boeing 737-300, Boeing 767-200; moreover, they made relinquishment, sales and decline to lease certain aircrafts in order to be suitable with their needs in the later changes of flight routes. This operation helped them reduce more than 130 fleets, which diminished $11 \%$ at the end of the period, and also gained $\$ 98$ million non-cash benefits in the process. The adjustment in focus of domestic routes to international flights also established a transcendent accomplishment. In the progress of reorganization, more than 50 new international routes was added, and, to meet the international demand, cincinnati---one of the main hubs of Delta---decreased its capacity by $25 \%$ for improving the local traffic in order to strengthen domestic hubs to meet the growing international service. In addition, since 2006, Delta has been increasing the number of wide-body aircrafts from domestic routes to international routes, rising approximately $20 \%-22 \%$ in international capacity compared to 2005 (Figure 4); it also brought a $24 \%$ increase in international passenger revenue.

\begin{tabular}{|lcc|}
\hline & 4Q 2006 & Full Year 2006 \\
\hline System & & \\
Domestic & Down 2 - 4\% & Down 5 - 7\% \\
International & Down 9-11\% & Down 12 - 14\% \\
& Up 21 - 23\% & Up 20 - 22\% \\
Mainline & & \\
Domestic & Down 3 - 5\% & Down 5 - 7\% \\
International & Down 12-14\% & Down 15 - 17\% \\
\hline
\end{tabular}

Figure 42006 capacity guidance [10]

Nevertheless, labor cost and pension, the most intractable issues, were needed to address urgently. The correspondent solution was composed of major two parts: Pension curtailment, Labor Reduction.

\subsection{Pension curtail}

Pension program was provided for the pilots and nonpilots who retired with a series of post-retirement benefits [11]. However, the pension for pilots was frozen at the end of 2005 due to the relief for the cost structure, which 
was permitted by the bankruptcy court---Delta was not affordable from the lump sum costs of Pilot Plan which, according to the Pension Protection Plan of 2006, was allowed to terminate. The result of termination was so noticeable that it had 5.2 million settlement gain [12]. Additionally, the agreement with the existing retirees on the reduction of their medical benefits contributed to $\$ 50$ millions in annual savings, and eliminating the healthcare coverage subsidy helped Delta gain a total of $\$ 527$ millions.

\subsection{Labor Reduction}

After a long period of deadlock in the negotiation with Air Line Pilots Association, International ("ALPA"), they finally settled down a temporary agreement in the salary reduction: $14 \%$ reduction in hourly pilot wage and other pilot costs items in correspondence to $1 \%$ decrease in hourly wage, which could be expected to save $\$ 280$ millions from average annual pilot costs. Besides, in the end of 2005, 6000-7000 employees were reduced in correspondence with a \$194 millions charges including $\$ 152$ millions special termination benefits and $\$ 42$ millions the employee severance.

\subsection{Exit from bankruptcy}

On April 30, 2007, after 19 months restructuring processes, Delta emerged from bankruptcy and was better positioned with a brand-new appearance in facing the new era of the career by completing the reorganization one year ahead of schedule [13]. In the first quarter of 2007 , Delta was profited with $\$ 155$ millions and reduced more the $50 \%$ on its net debt from $\$ 16.9$ billions in 2005 to $\$ 7.6$ billions at the end of 2007 .

\subsection{Summary}

From my personal perspective, cost structure is always a pivotal part regarding all businesses since we are not able to subjectively operate the environment of industry to achieve the revenue for gaining profit as we want. Therefore, companies should mainly embark on the scope that they can make reasonable adjustments for future prosperity. In the example of Delta, it was burdened by huge amounts of costs with relatively lower revenues, which resulted in the predicament that it faced at the start of $21 \mathrm{st}$ century. To some extent, the consequences that Delta had were caused by negligence in the awareness of future circumstances, whether the pension plan or the fuel cost---even though they were able to obtain enough oil supplies from hedging program during the period of reorganization. In the aviation industry, hedging contracts is a practicable strategy for reducing the fuel costs, implemented by locking oil prices in a specific price during the period of contracts. It is a risky tactic since companies should have extraordinarily accurate evaluations on the tendency of future prices.
Southwest airlines can be recognized as the most splendid carrier in hedging fuel prices that it held lower fuel prices compared with others in industry since 2001 . As a result, companies and decision makers must not only pay attention in the recent situation but also be sagacious regarding future tendency to maintain a stable cost structure. For current companies who are suffering from the consequences brought by covid-19, I would recommend that they must survive during this period by maintaining a reasonable cost structure and cutting redundant business operations. It will be the opportunity for them to find the approaches that will be most suitable to gain long-term profits after extricating from this plight.

\section{CONCLUSION}

The paper majorly illustrated the solution of cutting cost in the aircraft fees and labor expenses, which accounted for a great proportion in Delta's cost structure. Cost structure crucially determines how far a company can keep operating. From the example of Delta, the reducing cost structure provided a flexible prospect for its future prosperity opportunities by disposing its unintentional weaknesses of its previous operation. It can be considered as a juncture of reformation of a company for rising up into a more extraordinary level. Therefore, any company in the coronavirus period can use the example of Delta Airline as a potential solution to help rebound from a similar predicament; it reflected how to deal the issue from the aspect of cost structure. Due to each company's uniqueness, not all companies can apply the same approach; this paper can provide some inspirations for other companies in dealing with their own situations.

\section{AUTHORS' CONTRIBUTIONS} Chen.

This paper is independently completed by Panyue

\section{ACKNOWLEDGMENTS}

Sincerely, I am particularly grateful to professor Lichtenberg and teacher Cuihong Wang, who have gave me a lot of advice since the start of my writing and patiently answered all my questions and concerns. Additionally, I want to express my heartfelt thanks to my friend Jessie Zhao, who gave me ideas in organizing my paper.

\section{REFERENCES}

[1] current economic condition. Aug 282021. http://www.villaregine.com/vvrha/currenteconomic-condition.

[2] Coronavirus: impact on the aviation industry worldwide - statistics \& facts. Aug 3, 2021. 
https://www.statista.com/topics/6178/coronavirusimpact-on-the-aviation-industry-worldwide/

[3] Oil 2004-2008-Rising Prices https://www.globalsecurity.org/military/intro/oil2.htm

[4] Robert Pirog, World Oil Demand and its Effect on Oil Prices, 2005, pp.2-6.

[5] Jason Tokin, Airline Bankruptcy: The Determining Factors Leading to an Airline's Decline, 2010, pp. 27-32.

[6] Mary Jane Credeur, \$5B burden: Delta seeks relief from crushing pension obligations, Mar 28, 2005, https://www.bizjournals.com/atlanta/stories/2005/0 3/28/story1.html.

[7] ANNUAL REPORT PURSUANT TO SECTION 13 OR 15(d) OF THE SECURITIES EXCHANGE ACT OF 1934 For the fiscal year ended December 31, 2005. Mar 2006. https://d1lge852tjjqow.cloudfront.net/CIK0000027904/a240532f-e2cf-426c-b777d8cba5d32d02.pdf

[8] Delta sets industry record for worst year ever, Jan 20, 2005. https://www.nbcnews.com/id/wbna6847476.

[9] Staff Writer, Delta Air Lines Secure \$2.5 millions Exit Financing, Jan $30 \quad 2007$. https://news.delta.com/delta-air-lines-secures-25billion-exit-financing.

[10] CURRENT REPORT Pursuant to Section 13 OR 15(d) of the Securities Exchange Act of 1934, Nov 13 , 2006. https://d1lge852tjjqow.cloudfront.net/CIK0000027904/b4db629c-0a42-444b-b124b2a4bae7f406.pdf.

[11] ANNUAL REPORT PURSUANT TO SECTION 13 OR 15(d) OF THE SECURITIES EXCHANGE ACT OF 1934 For the fiscal year ended December 31, 2006, Mar 03, 2007. https://d1lge852tjjqow.cloudfront.net/CIK0000027904/6616ea9b-211a-47b3-9e2b1c5d74c5ea74.pdf.

[12] Delta Air Lines Reports Results for September 2006 Quarter, Nov 09, 2006. https://www.globenewswire.com/newsrelease/2006/11/09/350866/4057/en/Delta-AirLines-Reports-Results-for-September-2006Quarter.html

[13] Staff Writer, Delta Air Lines Exits Chapter 11 Stronger and Better Positioned for New Era of Competition, Apr $\quad 30, \quad 2007$. https://news.delta.com/delta-air-lines-exits-chapter- 11-stronger-and-better-positioned-new-eracompetition. 